\title{
miR-514a-3p functions as a tumor suppressor in renal cell carcinoma
}

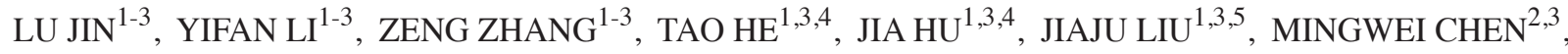

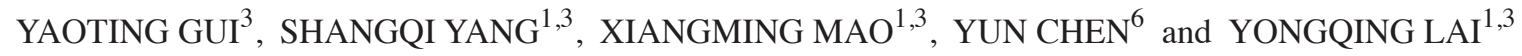 \\ ${ }^{1}$ Department of Urology, Peking University Shenzhen Hospital, Shenzhen, Guangdong 518036; \\ ${ }^{2}$ Department of Urology, Anhui Medical University, Hefei, Anhui 230032; ${ }^{3}$ The Guangdong and \\ Shenzhen Key Laboratory of Male Reproductive Medicine and Genetics, Shenzhen, Guangdong 518036; \\ ${ }^{4}$ Department of Urology, Guangzhou Medical University, Guangzhou, Guangdong 511436; ${ }^{5}$ Department of \\ Urology, Shantou University Medical College, Shantou, Guangdong 515041; ${ }^{6}$ Department of \\ Ultrasound, Peking University Shenzhen Hospital, Shenzhen, Guangdong 518036, P.R. China
}

Received March 7, 2016; Accepted February 27, 2017

DOI: $10.3892 / \mathrm{ol} .2017 .6855$

\begin{abstract}
Renal cell carcinoma (RCC) is the most common type of kidney cancer, and the prognosis of metastatic RCC remains poor with a high rate of recurrence and mortality. A previous study has revealed that microRNA (miRNA), which negatively regulates protein expression, serves a role of oncogene or tumor suppressor. The aim of the present study was to investigate the expression and function of miR-514a-3p in RCC. To detect the expression of miR-514a-3p in 32 paired RCC tissues, quantitative polymerase chain reaction (qPCR) was performed. The function of miR-514a-3p in the proliferation, mobility and apoptosis of RCC cells (786-O and ACHN) was assessed by MTT, CCK-8, cell scratch, Transwell, Hoechst 33342 staining and flow cytometry assay. The results of qPCR revealed that miR-514a-3p was significantly downregulated in RCC tissues compared with adjacent normal tissues. Upregulation of miR-514a-3p by transfection of mimics suppressed RCC cell proliferation, migration and invasion, and induced cell apoptosis. The results revealed that miR-514a-3p was significantly downregulated in RCC and may serve a role as tumor suppressor in RCC. Further studies are required, focusing on the possibility of using miR-514a-3p
\end{abstract}

Correspondence to: Professor Yongqing Lai, Department of Urology, Peking University Shenzhen Hospital, 1120 Lianhua Road, Shenzhen, Guangdong 518036, P.R. China

E-mail: yqlord@163.com

Professor Yun Chen, Department of Ultrasound, Peking University Shenzhen Hospital, 1120 Lianhua Road, Shenzhen, Guangdong 518036, P.R. China

E-mail: cyun126@126.com

Key words: microRNA, miR-514a-3p, renal cell carcinoma, tumor suppressor as a biomarker for RCC as well as the pathway of miR-514a-3p in RCC.

\section{Introduction}

Renal cell carcinoma (RCC), the third most common urological cancer, accounts for $\sim 3 \%$ of all adult malignancies and represents $90 \%$ of all kidney cancers $(1,2)$. Estimated cancer statistics in the USA revealed that RCC was among the top ten cancer types in terms of its incidence and mortality rate, with 63,920 new cancer cases and 13,860 mortalities from kidney and renal pelvis cancer estimated to occur in 2014 (3). For early and local RCC, surgical resection remains the best curative therapy approach, while $20-30 \%$ of patients develop local and/or distant disease recurrence (4). For advanced RCC, surgical resection has no curative effect and the disease is resistant to standard chemotherapy and radiotherapy, with a five-year survival rate of $<10 \%$ for patients with metastatic $\operatorname{RCC}(5,6)$. Thus, it is essential to understand the mechanisms of RCC tumorigenesis and development, and to search for novel biomarkers to improve the clinical outcomes of RCC.

MicroRNAs (miRNAs/miRs) are a class of non-coding RNAs with a length of $\sim 22$ nucleotides $(7,8)$. They regulate gene expression post-transcriptionally by imperfectly binding with the 3'-untranslated region (3'UTR) of targeted messenger RNAs (mRNAs) to suppress translation or induce mRNA degradation (7). miRNAs regulate various cellular processes including cell differentiation, proliferation, metabolism and apoptosis (1). Investigations of miRNAs have provided a new direction in our understanding of the mechanisms of tumorigenesis of RCC. A number of miRNAs have been observed to be deregulated in RCC, including miR-206 (9), miR-30c (10) and miR-29b (11). Previous studies of microarrays indicated that miR-514a-3p (previously known as miR-514) was downregulated in RCC $(12,13)$, although the expression of miR-514a-3p has not been verified in RCC tissues by quantitative polymerase chain reaction (qPCR). In the present study, the expression of miR-514a-3p in RCC and adjacent normal 
tissues was explored and the function of miR-514a-3p in RCC cell lines was assessed.

\section{Materials and methods}

Sample collection. A total of 30 paired tissues (RCC and adjacent normal tissues) were collected from Peking University Shenzhen Hospital (Guangdong, China). The adjacent normal tissues were extracted at $2 \mathrm{~cm}$ away from visible RCC lesions. Written informed consent was obtained from all patients. The collection and usage of the samples was reviewed and approved by the Ethics Committees of Peking University Shenzhen Hospital. The tissues were immersed in RNAlater for over 30 min (Qiagen, Hilden, Germany) after being dissected, and then stored at $-80^{\circ} \mathrm{C}$. The tissues collected were reviewed and classified by hematoxylin and eosin staining. The clinical and pathological characteristics of the patients are presented in Table I.

Cell culture. Two RCC cell lines (786-O and ACHN; American Type Culture Collection, Manassas, VA, USA) were used in this study. Cells were cultured in a humidified incubator containing $5 \% \mathrm{CO}_{2}$ at a temperature of $37^{\circ} \mathrm{C}$ in Dulbecco's modified Eagle's medium (DMEM; Gibco; Thermo Fisher Scientific, Inc., Waltham, MA, USA) with $10 \%$ fetal bovine serum (FBS; Gibco), $1 \%$ antibiotics $(100 \mu \mathrm{l} / \mathrm{ml}$ penicillin and $100 \mathrm{mg} / \mathrm{ml}$ streptomycin sulfates; Gibco) and $1 \%$ glutamine (Gibco).

RNA extraction, cDNA synthesis and $q P C R$. Total RNA was extracted from the samples and cells by TRIzol reagent (Invitrogen; Thermo Fisher Scientific, Inc.) and purified with the RNeasy maxi kit (Qiagen) according to the manufacturer's protocol. The RNA concentration was measured using a NanoDrop 2000/2000c (Thermo Fisher Scientific, Inc.). One microgram of RNA from each sample was used to obtain cDNA by performing reverse transcription PCR with a miScript reverse transcription kit (Qiagen). Then qPCR was performed with a miScript SYBR-Green PCR kit (Qiagen) on the Roche Lightcycler 480 real-time PCR system (Roche Diagnostics, Basel, Switzerland). U6 was used as an internal control and the sequences of the primers are shown in Table II. The thermocycling conditions were as follows: $95^{\circ} \mathrm{C}$ for $1 \mathrm{~min}$, then 40 cycles of $95^{\circ} \mathrm{C}$ for $10 \mathrm{sec}, 55^{\circ} \mathrm{C}$ for $30 \mathrm{sec}$ and $70^{\circ} \mathrm{C}$ for $30 \mathrm{sec}$. The expression levels of miR-514a-3p in tissues and cells were analyzed with the $2^{-\Delta \Delta \mathrm{Cq}}$ method.

Cell transfection. Synthesized miR-514a-3p mimic (GenePharma, Suzhou, China) or mimic negative control (NC) were transfected into cells with Lipofectamine ${ }^{\circledR} 2000$ (Invitrogen), which was mixed in Opti-MEM ${ }^{\circledR}$ I reduced serum medium (Gibco) according to the manufacturer's protocol. qPCR was performed to measure the expression of miR-514a-3p in cells following transfection. The sequences used in the study are shown in Table II.

Cell scratch assay. Cell scratch assay was performed to assess the cell migratory ability of 786-O and ACHN cells. Approximately $3 \times 10^{5}$ cells were seeded in each well of a six-well plate. Twenty-four h later, the cells were transfected
Table I. Clinicopathological features of renal cell carcinoma patients.

\begin{tabular}{lc}
\hline Characteristics & Number of cases \\
\hline Mean age (range) (years) & $50(25-70)$ \\
Sex & $19 / 11$ \\
Male/female & \\
Histological type & $25 / 5$ \\
Clear cell/papillary & \\
pT stage & $18 / 8 / 4$ \\
T1/T2/T3 +T4 & \\
Fuhrman grade & $18 / 7 / 5$ \\
I/II/III+IV & \\
AJCC clinical stages & $17 / 8 / 5$ \\
I/II/III+IV & \\
\hline
\end{tabular}

pT, primary tumor; AJCC, American Joint Committee on Cancer.

Table II. Sequences used in the study.

\begin{tabular}{|c|c|}
\hline & Sequence \\
\hline \multirow{3}{*}{$\begin{array}{l}\operatorname{miR}-514 a-3 p \\
\text { mimic }\end{array}$} & Sense: 5'-AUUGACACUUCUGUG \\
\hline & AGUAGA-3' \\
\hline & $\begin{array}{l}\text { Antisense: 5'-UACUCACAGAAGU } \\
\text { GUCAAUUU-3' }\end{array}$ \\
\hline \multirow[t]{2}{*}{ Negative control } & $\begin{array}{l}\text { Sense: 5'-UUCUCCGAACGUGUC } \\
\text { ACGUTT-3' }\end{array}$ \\
\hline & $\begin{array}{l}\text { Antisense: 5'-ACGUGACACGUUC } \\
\text { GGAGAATT-3' }\end{array}$ \\
\hline Inhibitor NC & $\begin{array}{l}\text { 5'-CAGUACUUUUGUGUAGUAC } \\
\text { AA-3' }\end{array}$ \\
\hline U6 forward primer & 5'-CTCGCTTCGGCAGCACA-3' \\
\hline U6 reverse primer & 5'-ACGCTTCACGAATTTGCGT-3' \\
\hline $\begin{array}{l}\operatorname{miR}-514 a-3 p \\
\text { forward primer }\end{array}$ & 5'-ATTGACACTTCTGTGAGTAGA-3' \\
\hline $\operatorname{miR}-514 a-3 p$ & Universal primer (miScript SYBR- \\
\hline reverse primer & Green PCR kit) \\
\hline
\end{tabular}

NC, negative control.

with miR-514a-3p mimics or mimic NC. At $6 \mathrm{~h}$ after transfection the cell monolayer was scratched with a sterile 1-ml pipette tip to generate a line-shaped wound. To remove the floating cells every well was rinsed with phosphate-buffered saline (PBS). Then the cells were cultured in DMEM supplemented with 5\% FBS. A digital camera system was used to acquire images of the scratches at 0 and $24 \mathrm{~h}$ after making the scratch. The experiments were performed in triplicate and repeated three times.

Cell proliferation assay. 3-(4,5-dimethylthiazol-2-yl)-2, 5-diphenyltetrazolium bromide (MTT) assay and CCK-8 


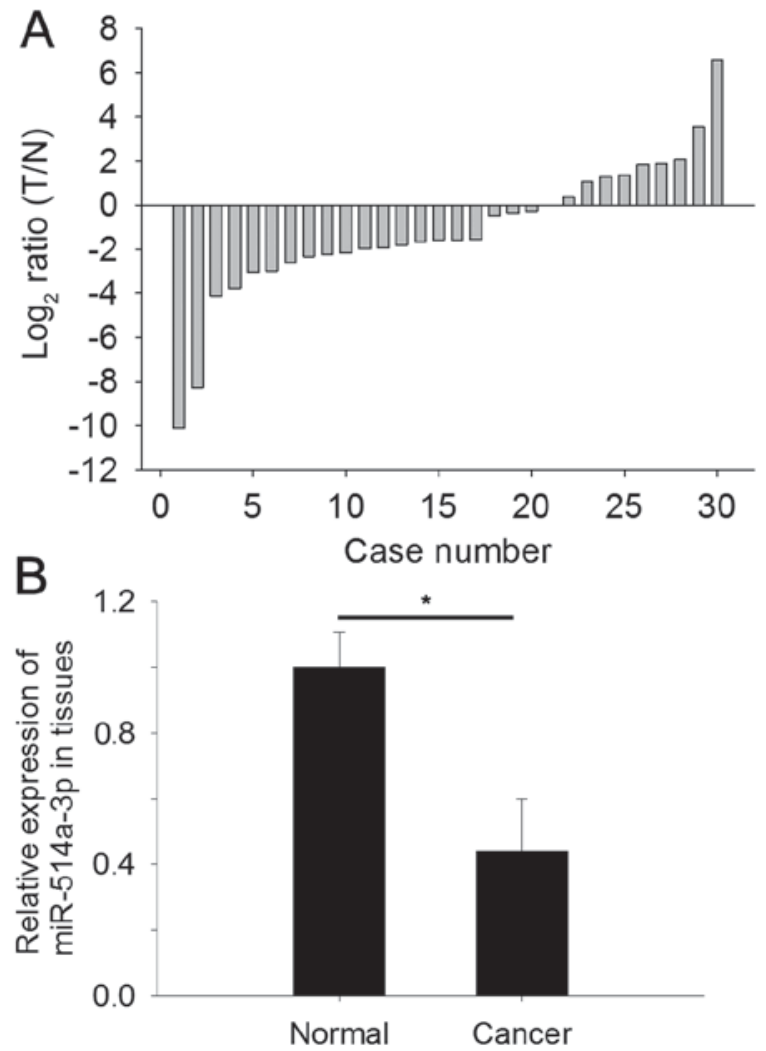

Figure 1. Expression of miR-514a-3p. (A) $\log _{2}$ ratios (T/N) of miR-514a-3p in 30 paired tissues (where T represents RCC tissues and $\mathrm{N}$ represents normal tissues). (B) Relative expression of miR-514a-3p in RCC and normal tissues. ${ }^{*} \mathrm{P}<0.05$. RCC, renal cell carcinoma.

assay were performed to assess cell proliferative ability following transfection. A total of 5,000 cells were seeded in each well of a 96-well plate and $12 \mathrm{~h}$ later the cells were transfected with miR-514a-3p mimics or mimic NC. For the CCK- 8 assay, $10 \mu 1$ Cell Counting Kit-8 (CCK-8, Beyotime Institute of Biotechnology, Shanghai, China) was added into the wells for detection at $0,24,48$ and $72 \mathrm{~h}$ after transfection, and $1 \mathrm{~h}$ later the optical density (OD) of each well was measured using an ELISA microplate reader (Bio-Rad Laboratories, Inc., Hercules, CA, USA) at a wavelength of $490 \mathrm{~nm}$. For the MTT assay, $20 \mu 1$ MTT $(5 \mathrm{mg} / \mathrm{ml}$; Sigma-Aldrich; Merck KGaA, Darmstadt, Germany) was added into the wells for detection at $0,24,48$ and $72 \mathrm{~h}$ after transfection, and $4 \mathrm{~h}$ later the mixed medium was replaced by $150 \mu 1$ dimethylsulfoxide (Sigma-Aldrich; Merck KGaA). Next, the 96-well plate was agitated for $15 \mathrm{~min}$ at room temperature. Then the OD of each well was measured by the ELISA microplate reader at a wavelength of $490 \mathrm{~nm}$. The experiments were performed in sextuplicate and repeated at least three times.

Transwell assay. Transwell assay was performed to assess the cell migratory and invasive ability. In the assay, Transwell chamber inserts (BD Biosciences, New York, NJ, USA) with (for migration) or without Matrigel (BD; for invasion) were used following the manufacturer's protocol. Transfected cells $\left(1 \times 10^{4}\right)$ in $200 \mu 1$ DMEM were seeded in the upper channel of the inserts. Cells were allowed to migrate for $36 \mathrm{~h}$ and invade

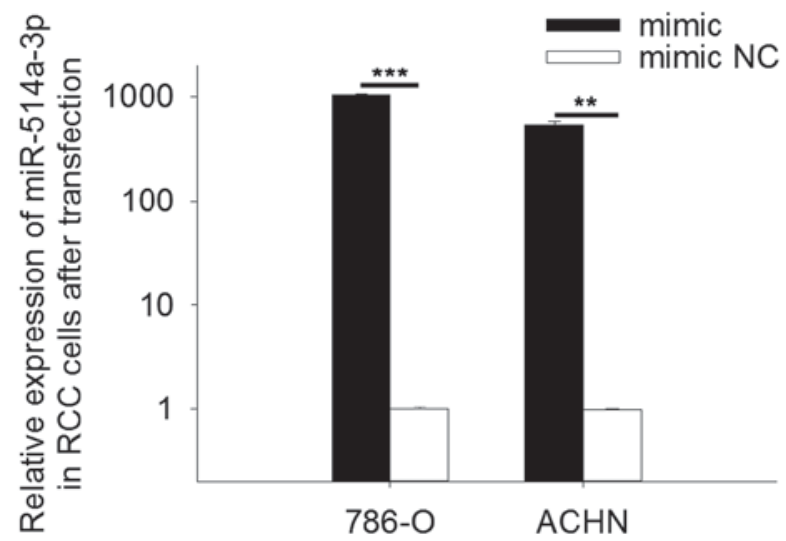

Figure 2. Relative expression of miR-514a-3p in 786-O and ACHN cells following transfection. ${ }^{* *} \mathrm{P}<0.01,{ }^{* * *} \mathrm{P}<0.001$. RCC, renal cell carcinoma.

for $48 \mathrm{~h}$. The cells that migrated or invaded to the bottom of the inserts were stained with crystal violet for $25 \mathrm{~min}$ and then washed with PBS 3 times. The cells would be counted using a microscope. The experiments were performed in triplicate and repeated at least three times.

Hoechst 33342 staining assay. Approximately $3 \times 10^{5}$ cells were seeded in each well of a six-well plate, and $12 \mathrm{~h}$ later the cells were transfected with miR-514a-3p mimics or mimic NC. After 48 h the cells were stained with Hoechst 33342 $(5 \mu \mathrm{g} / \mathrm{ml}$; Thermo Fisher Scientific, Inc.) for $20 \mathrm{~min}$. Images of the cells were acquired with an immunofluorescent inverted fluorescence microscope (Leica DM IRB, Wetzlar, Germany) after washing twice in PBS.

Flow cytometry assay. The apoptotic rates of cells were measured by performing flow cytometry assay with an Alexa Fluor $^{\circledR} 488$ Annexin V/dead cell apoptosis kit (Invitrogen). Approximately $3 \times 10^{5}$ cells were seeded in each well of a six-well plate and $12 \mathrm{~h}$ later the cells were transfected with miR-514a-3p mimics or mimic NC. At $48 \mathrm{~h}$ after transfection all cells were harvested and stained according to the manufacturer's protocol. After 15 min of staining, $400 \mu \mathrm{l}$ binding buffer (provided with the apoptosis kit) was added to each tube. Then flow cytometry (EPICS XL-4; Beckman Coulter, Inc., Brea, CA, USA) was used to analyze the apoptosis rate. The experiments were performed in triplicate and repeated at least three times.

Statistical analysis. A paired t-test was used to compare the expression levels of miR-514a-3p in matched tumor/normal tissues and cells. Student's t-test was used to analyze assays for characterizing phenotypes of cells. All statistical analyses were carried out using the SPSS 19.0 statistical software package (IBM SPSS, Armonk, NY, USA). The results in all figures are shown as the means \pm standard error. $\mathrm{P}<0.05$ was considered to indicate a statistically significant difference.

\section{Results}

miR-514a-3p is downregulated in RCC tissues. To determine the expression level of miR-514a-3p, qPCR was performed in 30 paired RCC tissues and adjacent normal tissues. The 

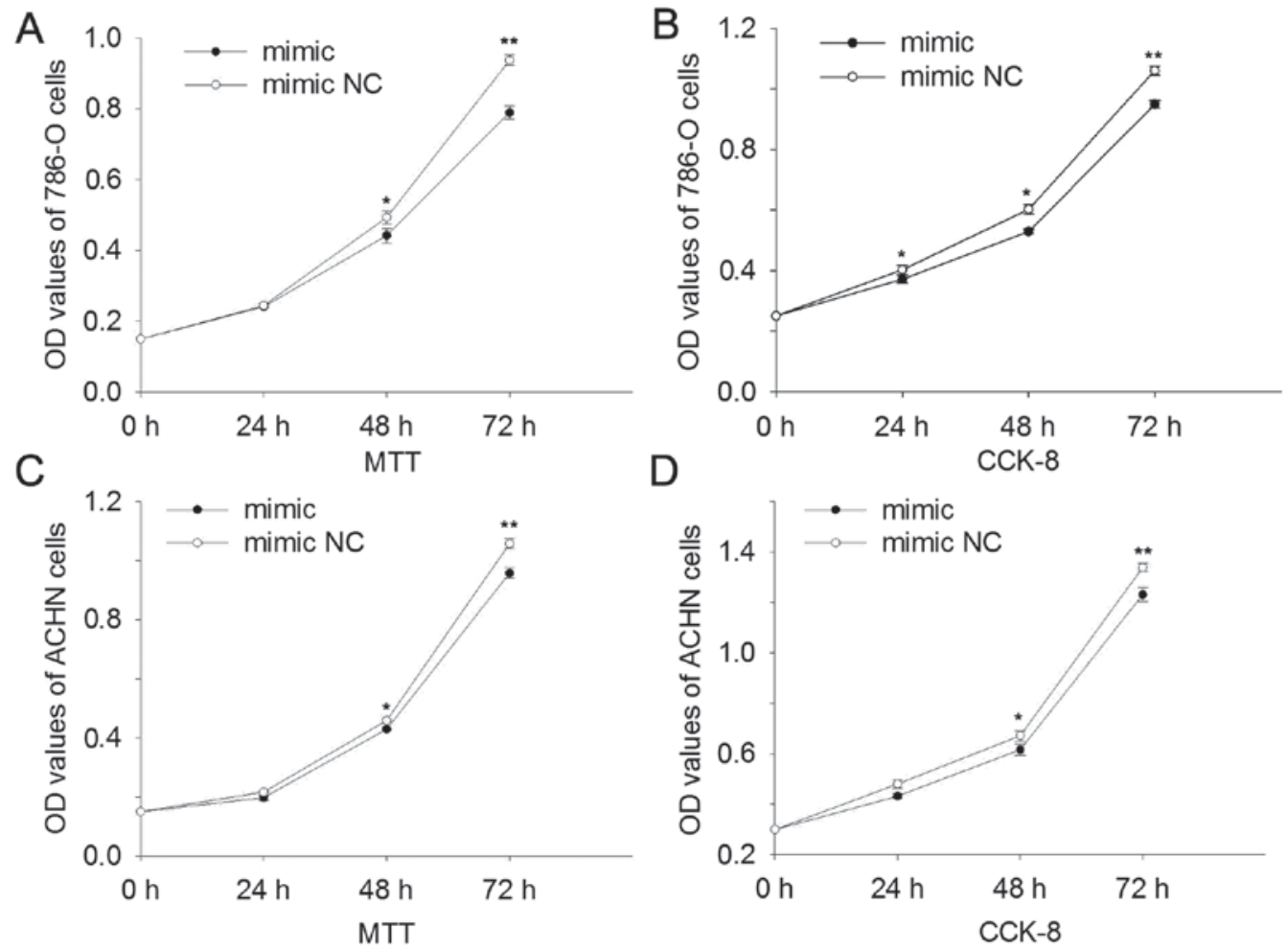

Figure 3. Cell proliferation assay of 786-O (A and B) and ACHN (C and D) cells. Results of MTT (A and C) and CCK-8 (B and D) assay revealed that overexpression of miR-514a-3p inhibited cell proliferation. ${ }^{*} \mathrm{P}<0.05,{ }^{, *} \mathrm{P}<0.01 \mathrm{vs}$. mimic NC. OD, optical density; NC, negative control.

relative expression of miR-514a-3p $[\log 2(\mathrm{~T} / \mathrm{N})$, where T represents RCC tissues and $\mathrm{N}$ represents normal tissues] in tissues is shown in Fig. 1A. The relative expression of miR-514a-3p in RCC $(0.44 \pm 0.16)$ was significantly lower compared with adjacent normal tissues, as shown in Fig. 1B ( $<<0.05)$.

Validation of expression ofmiR-514a-3p following transfection . To determine the expression level of miR-514a-3p following transfection, qPCR was performed. The results revealed that in cells transfected with miR-514a-3p mimics the expression of miR-514a-3p was 1043.84 times higher $(786-\mathrm{O}$ cells, $\mathrm{P}<0.001)$ and 541.09 times higher $(\mathrm{ACHN}$ cells, $\mathrm{P}<0.01)$ than in cells transfected with mimic NC. The results are shown in Fig. 2.

miR-514a-3p suppresses cell proliferation. MTT and CCK-8 assays were performed, and the results suggested that upregulation of miR-514a-3p suppressed cell proliferation. In $786-\mathrm{O}$ cells the results revealed that at 24,48 and $72 \mathrm{~h}$ the cell proliferation was reduced by $1.37,10.40(\mathrm{P}<0.05)$ and $15.78 \%(\mathrm{P}<0.01)$ (MTT assay, Fig. 3A) and $7.68(\mathrm{P}<0.05)$, $12.17(\mathrm{P}<0.05)$ and $10.50 \%(\mathrm{P}<0.01)(\mathrm{CCK}-8$ assay, Fig. 3B $)$ compared with cells transfected with mimic NC. In ACHN cells the results revealed that at 24,48 and $72 \mathrm{~h}$ the cell proliferation was reduced by $8.68,6.46(\mathrm{P}<0.05)$ and $9.50 \%(\mathrm{P}<0.01)(\mathrm{MTT}$ assay, Fig. 3C) and 9.92, $8.24(\mathrm{P}<0.05)$ and $8.02 \%(\mathrm{P}<0.01)$ (CCK-8 assay, Fig. 3D). The results revealed that miR-514a-3p suppressed cell proliferation in RCC.

miR-514a-3p suppresses RCC cell mobility. Cell scratch assay and Transwell assay were performed to assess cell mobility. The results of cell scratch assay revealed that in cells transfected with miR-514a-3p mimics the migratory distance was reduced by $67.29 \%(786-\mathrm{O}, \mathrm{P}<0.01)$ and $27.26 \%(\mathrm{ACHN}, \mathrm{P}<0.05)$ compared with cells transfected with mimic $\mathrm{NC}$, as shown in Fig. 4A and B. The results of Transwell assay revealed that upregulation of miR-514a-3p suppressed cell migration and invasion. As shown in Fig. 5A, the invasive 786-O cell number was reduced by $40.61 \%(\mathrm{P}<0.01)$ and migratory cells were reduced by $53.08 \%(\mathrm{P}<0.01)$ for cells transfected with miR-514a-3p mimics. For ACHN cells, upregulation of miR-514a-3p reduced invasive cells by $38.55 \%(\mathrm{P}<0.05)$ and migratory cells by $29.44 \%(\mathrm{P}<0.05)$, as shown in Fig. 5B. The results indicated that miR-514a-3p suppressed RCC cell mobility.

miR-514a-3p induces cell apoptosis. The apoptotic rate was qualified by flow cytometry and Hoechst 33342 staining. The results of flow cytometry indicated that the apoptotic rate of cells transfected with miR-514a-3p mimics or mimic NC was 21.08 vs. $10.32 \%(\mathrm{P}<0.01)$ in $786-\mathrm{O}$ cells $($ Fig. $6 \mathrm{~A})$ and 17.21 vs. 6.95\% ( $\mathrm{P}<0.01)$ in ACHN cells (Fig. 6B). The results of Hoechst 33342 staining are shown in Fig. 7, indicating that the apoptotic rate was 31.91 vs. $18.41 \%$ in $786-\mathrm{O}$ cells transfected with miR-514a-3p mimics vs. mimic NC (Fig. 7A). In ACHN cells the apoptotic rate was $37.86 \%$ in cells transfected with mimic and $12.17 \%$ in cells transfected with $\mathrm{NC}(\mathrm{P}<0.01$; Fig. 7B). The results revealed that miR-514a-3p induced cell apoptosis in RCC.

\section{Discussion}

Emerging evidence has highlighted the role of non-coding RNA in post-transcriptional regulation of human tumorigenesis. 

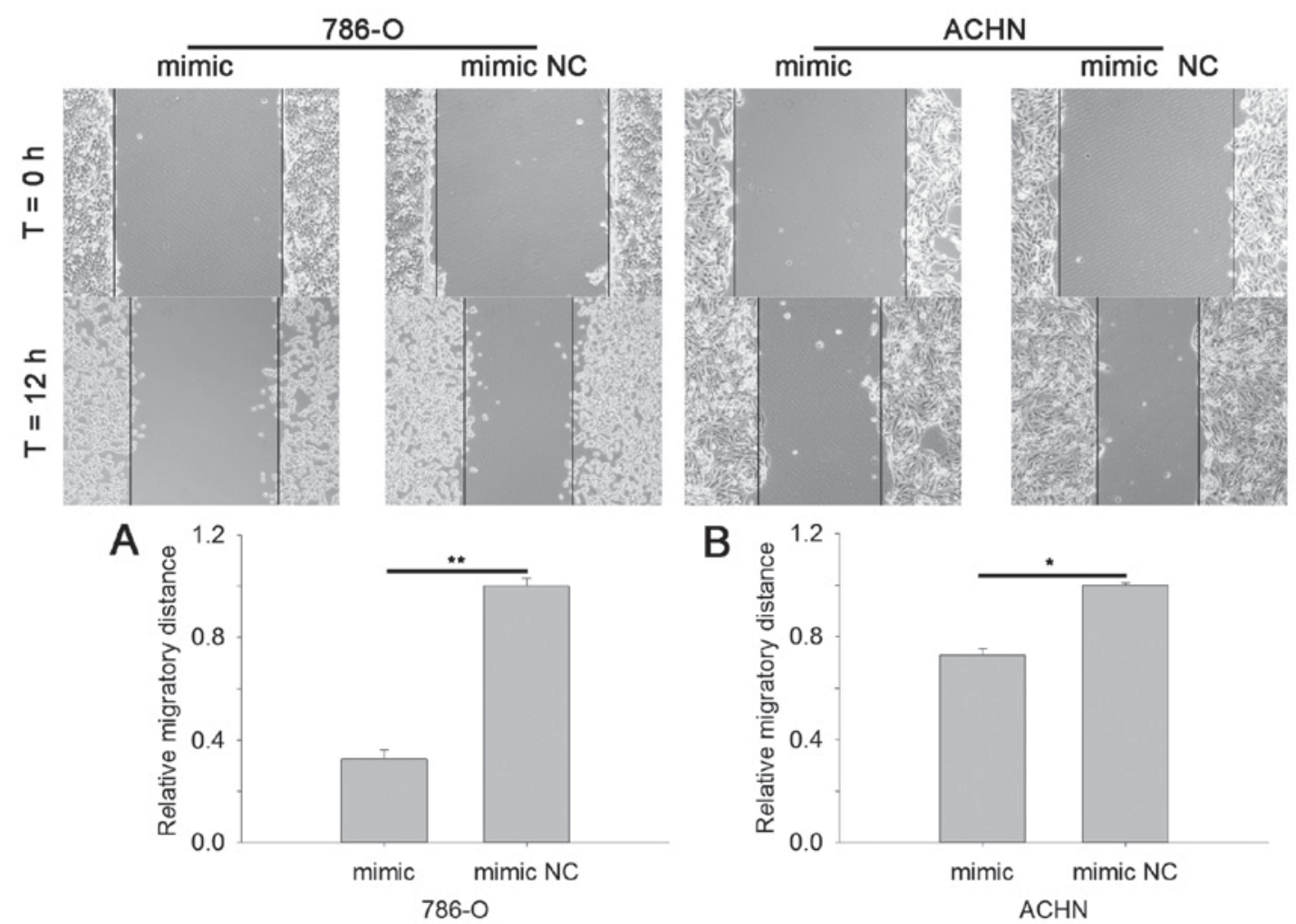

Figure 4. Cell scratch assay of 786-O (A) and ACHN (B) cells. Upregulation of miR-514a-3p inhibited 786-O and ACHN cell migration. Cells were stained with crystal violet for $25 \mathrm{~min}$, and visualized at magnification, $\mathrm{x} 200$. ${ }^{*} \mathrm{P}<0.05,{ }^{* * *} \mathrm{P}<0.01$. NC, negative control.

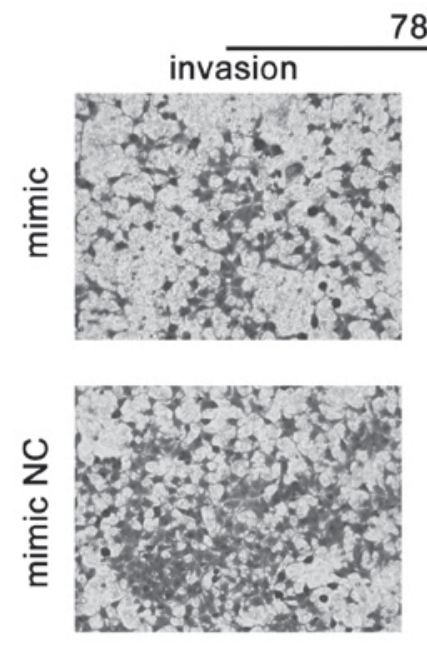

A

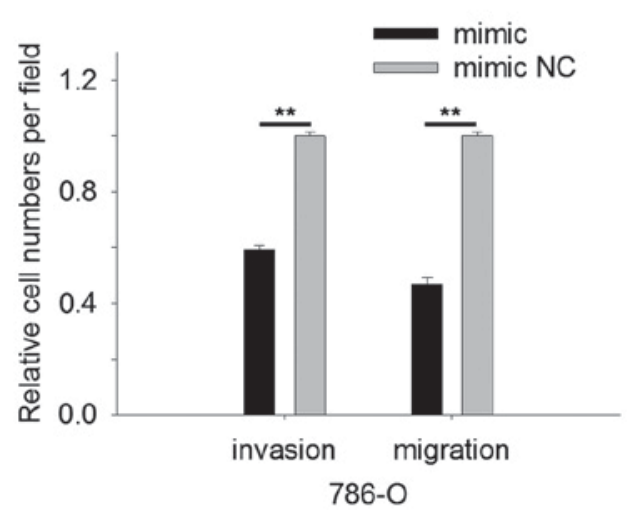

$786-0$
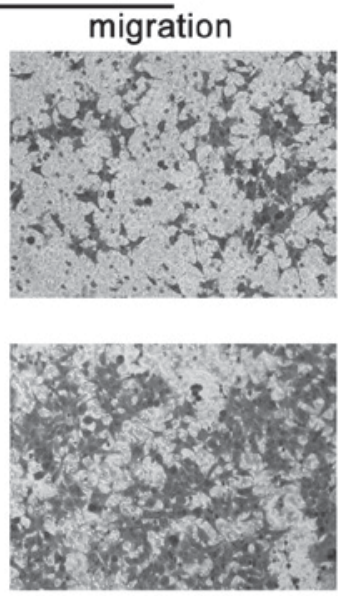

B
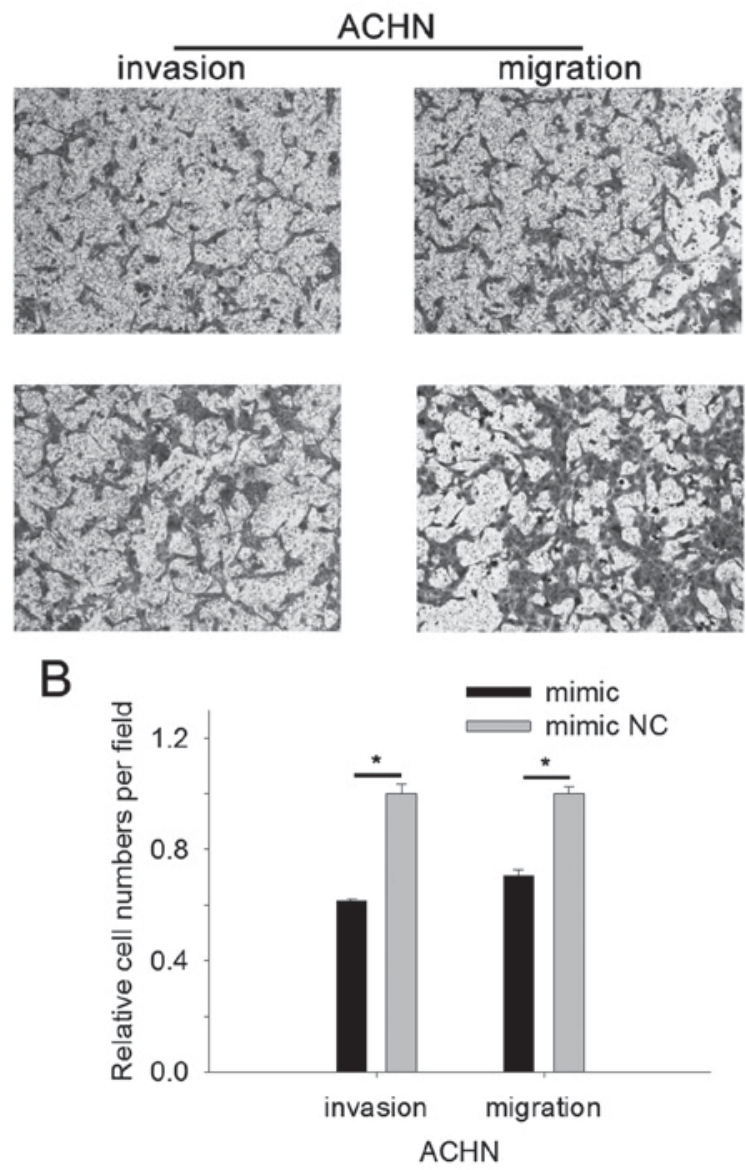

Figure 5. miR-514a-3p inhibits renal cell carcinoma cell migration and invasion. (A) Transwell assay revealed that overexpression of miR-514a-3p inhibited 786-O cell migration and invasion. (B) Similar results were observed in ACHN cells. Cells were stained with crystal violet for 25 min, and visualized at magnification, $\mathrm{x} 200 .{ }^{*} \mathrm{P}<0.05,{ }^{* *} \mathrm{P}<0.01$. NC, negative control. 

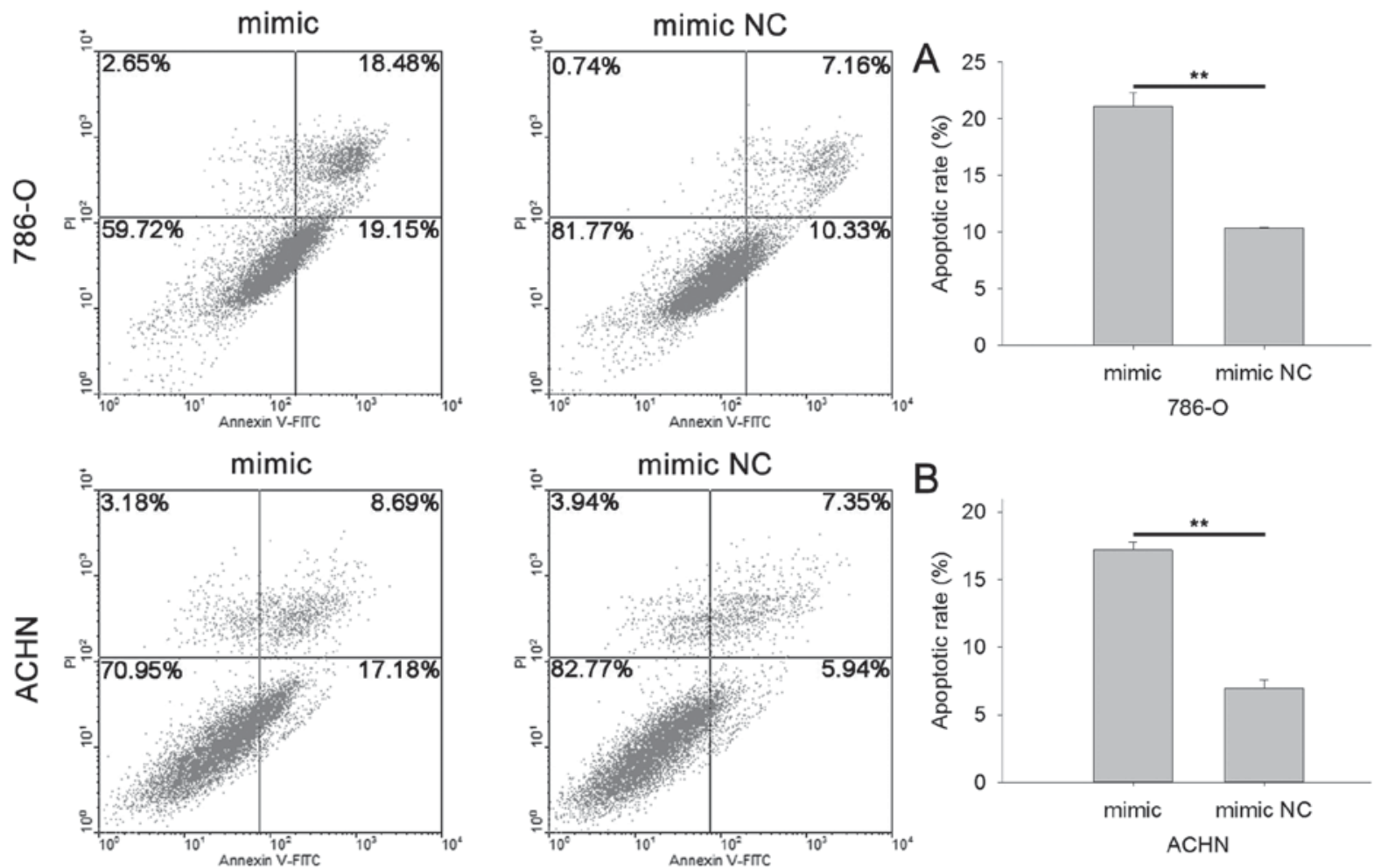

Figure 6. miR-514a-3p regulates renal cell carcinoma cell apoptosis. Upregulation of miR-514a-3p induced (A) 786-O and (B) ACHN cell apoptosis. ** $\mathrm{P}<0.01$. $\mathrm{NC}$, negative control.
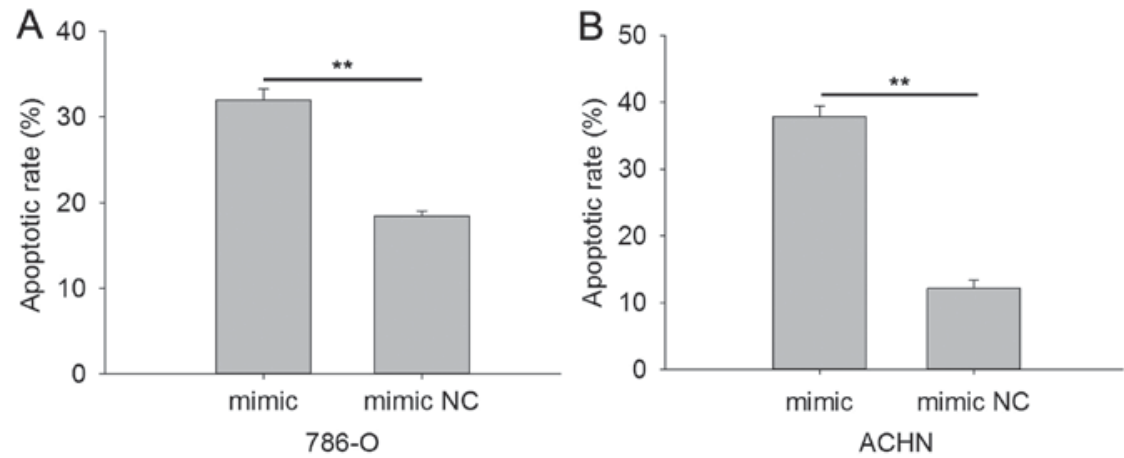

Figure 7. Hoechst 33342 staining assay revealed that the apoptotic rate was improved in (A) 786-O and (B) ACHN cells when miR-514a-3p was upregulated. ${ }^{* *} \mathrm{P}<0.01$. NC, negative control.

Non-coding RNAs are divided into three groups: long non-coding RNAs, small non-coding RNAs and housekeeping RNAs (14). miRNA is a kind of non-coding RNA which is generated through multiple processes (15-17). For most miRNA in mammals, the primary miRNAs (pri-miRNAs) are the transcripts transcribed by RNA polymerase II and at the length of 300-1,000 nucleotides. Pri-miRNA is processed in the nucleus by Drosha and DiGeorge syndrome critical region 8 to produce a small double-stranded hairpin-shaped pre-miRNA transcript, which is the precursor miRNA. Finally, the mature miRNA is generated with the help of Dicer (15-17). The mature miRNA regulates gene expression post-transcriptionally by binding with the 3'UTR of targeted mRNA (18-20).

Previous studies have revealed that miRNAs have unique expression profiles in different types of cancer or diseases at different stages, which indicates that miRNAs could be used as biomarkers for diagnosis and serve a significant role in the occurrence and development of tumors $(21,22)$. In RCC, certain miRNAs have been described as either oncogenes or tumor suppressors based on the function and expression level of miRNAs. For example, miR-29s, miR-1, miR-133a and miR-497 have been described as tumor suppressors for downregulation in $\operatorname{RCC}(5,23,24)$, and the downregulation of miR-497 is associated with a poor prognosis for RCC patients. Conversely, miR-29b, miR-21 and miR-210 are overexpressed in $\operatorname{RCC}(1,11)$, and high expression of miR-29b is associated with the tumor-node-metastasis stage and prognosis of RCC. Thus, miRNAs are potential biomarkers for diagnosis, prognostic judgment or targeted therapy in tumors.

miR-514a-3p (previously known as miR-514), located on chrXq27.3, has been demonstrated to be abnormally expressed in melanoma and metastatic $\operatorname{RCC}(25,26)$. In melanoma, 
Stark et al observed that miR-514a-3p negatively regulated nuclear factor 1 (NF1) and cyclin-dependent kinase 2 (CDK2) (26). Wotschofsky et al assessed the expression of miR-514a-3p in 111 RCC patients (22 cases with metastases and 89 without) and the results revealed that miR-514a-3p was further downregulated in metastatic RCC compared with non-metastatic RCC tissues (25). It was also indicated that miR-514a-3p could be used as an indicator of recurrence risk and an independent prognostic risk factor (25). In the present study, the results of qPCR revealed that miR-514a-3p was downregulated in RCC tissues compared with adjacent normal tissues. It was hypothesized that miR-514a-3p may serve a tumor suppressor role in RCC. In addition, RCC cellular function was assessed following overexpression of miR-514a-3p in RCC cells by transfecting miR-514a-3p mimics. It was observed that overexpression of miR-514a-3p suppressed RCC cell proliferation, migration and invasion, and induced RCC cell apoptosis. Thus, miR-514a-3p is a potential biomarker for RCC and may contribute to a better understanding of the mechanism of RCC. Taken together, the results of the present study demonstrated that miR-514a-3p served a role as tumor suppressor in RCC.

Few studies have investigated the unique expression profile of miR-514a-3p in different cancers. In melanoma, only NF1 and CDK2 were confirmed to be regulated by miR-514a-3p. It remains to be elucidated how miR-514a-3p functions as a tumor suppressor. Further study should focus on the mechanism of miR-514a-3p in RCC.

In conclusion, the results of the present study demonstrate that miR-514a-3p is significantly downregulated in RCC tissues and serves a role as tumor suppressor. Thus, miR-514a-3p is a potential biomarker for RCC. Further studies should be performed, focusing on the pathway of miR-514a-3p and the possibility of its use as a biomarker for RCC.

\section{Acknowledgements}

This study was supported by the National Natural Science Foundation of China (no. 81101922), the Guangdong Natural Science Foundation (no. 2015A030313889), the Science and Technology Development Fund Project of Shenzhen (nos. JCYJ20120616144352139, JCYJ20130402114702124, JCYJ20140415162542975 and JCYJ20150403091443329) and the Fund of Guangdong Key Medical Subject.

\section{References}

1. Neal CS, Michael MZ, Rawlings LH, Van der Hoek MB and Gleadle JM: The VHL-dependent regulation of microRNAs in renal cancer. BMC Med 8: 64, 2010.

2. Rasmussen F: Metastatic renal cell cancer. Cancer Imaging 13: 374-380, 2013.

3. Siegel R, Ma J, Zou Z and Jemal A: Cancer statistics, 2014, CA Cancer J Clin 64: 9-29, 2014.

4. Rini BI, Rathmell WK and Godley P: Renal cell carcinoma. Curr Opin Oncol 20: 300-306, 2008.

5. Zhao X, Zhao Z, Xu W, Hou J and Du X: Down-regulation of miR-497 is associated with poor prognosis in renal cancer. Int J Clin Exp Pathol 8: 758-764, 2015.

6. Ljungberg B, Bensalah K, Canfield S, Dabestani S, Hofmann F, Hora M, Kuczyk MA, Lam T, Marconi L, Merseburger AS, et al: EAU guidelines on renal cell carcinoma: 2014 update. Eur Urol 67: 913-924, 2015.
7. Huang J, Yao X, Zhang J, Dong B, Chen Q, Xue W, Liu D and Huang Y: Hypoxia-induced downregulation of miR-30c promotes epithelial-mesenchymal transition in human renal cell carcinoma. Cancer Sci 104: 1609-1617, 2013.

8. Luo Z, Zhang L, Li Z, Jiang C, Dai Y, Liu X, Zheng Y, Yu H, Xiang J and Li G: miR-149 promotes epithelial-mesenchymal transition and invasion in nasopharyngeal carcinoma cells. Zhong Nan Da Xue Xue Bao Yi Xue Ban 36: 604-609, 2011.

9. Cai Y, Li H and Zhang Y: Downregulation of microRNA-206 suppresses clear cell renal carcinoma proliferation and invasion by targeting vascular endothelial growth factor A. Oncol Rep 35: 1778-1786, 2016

10. Wang J, Duan L, Guo T, Gao Y, Tian L, Liu J, Wang S and Yang J: Downregulation of miR-30c promotes renal fibrosis by target CTGF in diabetic nephropathy. J Diabetes Complications 30: 406-414, 2016.

11. Xu Y, Zhu J, Lei Z, Wan L, Zhu X, Ye F and Tong Y: Expression and functional role of miR-29b in renal cell carcinoma. Int J Clin Exp Pathol 8: 14161-14170, 2015.

12. Tang $\mathrm{K}$ and $\mathrm{Xu} \mathrm{H}$ : Prognostic value of meta-signature miRNAs in renal cell carcinoma: An integrated miRNA expression profiling analysis. Sci Rep 5: 10272, 2015.

13. Nakada C, Matsuura K, Tsukamoto Y, Tanigawa M, Yoshimoto T, Narimatsu T, Nguyen LT, Hijiya N, Uchida T, Sato F, et al: Genome-wide microRNA expression profiling in renal cell carcinoma: Significant down-regulation of miR-141 and miR-200c. J Pathol 216: 418-427, 2008.

14. Esteller M: Non-coding RNAs in human disease. Nat Rev Genet 12: 861-874, 2011.

15. Miyoshi K, Miyoshi T and Siomi H: Many ways to generate microRNA-like small RNAs: Non-canonical pathways for microRNA production. Mol Genet Genomics 284: 95-103, 2010.

16. Ha M and Kim VN: Regulation of microRNA biogenesis. Nat Rev Mol Cell Biol 15: 509-524, 2014.

17. Denby L and Baker AH: Targeting non-coding RNA for the therapy of renal disease. Curr Opin Pharmacol 27: 70-77, 2016.

18. Li M, Wang Y, Song Y, Bu R, Yin B, Fei X, Guo Q and Wu B: MicroRNAs in renal cell carcinoma: A systematic review of clinical implications (Review). Oncol Rep 33: 1571-1578, 2015.

19. Huang X, Huang M, Kong L and Li Y: miR-372 suppresses tumour proliferation and invasion by targeting IGF2BP1 in renal cell carcinoma. Cell prolif 48: 593-599, 2015.

20. Liu XJ,Hong Q, Wang Z, Yu YY,Zou X and Xu LH: MicroRNA21 promotes interstitial fibrosis via targeting DDAH1: A potential role in renal fibrosis. Mol Cell Biochem 411: 181-189, 2016.

21. Su Z, Chen D, Zhang E, Li Y, Yu Z, Shi M, Jiang Z, Ni L, Yang S, Gui Y, et al: MicroRNA-509-3p inhibits cancer cell proliferation and migration by targeting the mitogen-activated protein kinase kinase kinase 8 oncogene in renal cell carcinoma. Mol Med Rep 12: 1535-1543, 2015.

22. Song T, Zhang X, Wang C, Wu Y, Cai W, Gao J and Hong B: MiR-138 suppresses expression of hypoxia-inducible factor $1 \alpha$ $(\mathrm{HIF}-1 \alpha)$ in clear cell renal cell carcinoma $786-\mathrm{O}$ cells. Asian Pac J Cancer Prev 12: 1307-1311, 2011.

23. Kawakami K, Enokida H, Chiyomaru T, Tatarano S, Yoshino H, Kagara I, Gotanda T, Tachiwada T, Nishiyama K, Nohata N, et al: The functional significance of miR-1 and miR-133a in renal cell carcinoma. Eur J Cancer 48: 827-836, 2012.

24. Nishikawa R, Chiyomaru T, Enokida H, Inoguchi S, Ishihara T, Matsushita R, Goto Y, Fukumoto I, Nakagawa M and Seki N: Tumour-suppressive microRNA-29s directly regulate LOXL2 expression and inhibit cancer cell migration and invasion in renal cell carcinoma. FEBS Lett 589: 2136-2145, 2015.

25. Wotschofsky Z, Busch J, Jung M, Kempkensteffen C, Weikert S, Schaser KD, Melcher I, Kilic E, Miller K, Kristiansen G, et al: Diagnostic and prognostic potential of differentially expressed miRNAs between metastatic and non-metastatic renal cell carcinoma at the time of nephrectomy. Clin Chim Acta 416: 5-10, 2013.

26. Stark MS, Bonazzi VF, Boyle GM, Palmer JM, Symmons J, Lanagan CM, Schmidt CW, Herington AC, Ballotti R, Pollock PM and Hayward NK: miR-514a regulates the tumour suppressor NF1 and modulates BRAFi sensitivity in melanoma. Oncotarget 6: 17753-17763, 2015. 